\title{
Title: What's citizenship got to do with mental health? A rationale for the inclusion of citizenship as part of a mental health strategy
}

\section{Introduction}

In this paper we explore the concept of citizenship and its potential application to the lived experiences of people with mental health problems (MHPs). We argue that citizenship can help frame people's experiences of marginalisation and can offer strategies to support their social inclusion. Through considering the "what, why, how and who" of citizenship, we provide a rationale for including citizenship as part of a person-centred and holistic mental health strategy. Set within a Scottish context and as part of the citizenship work package of the "Citizenship, Recovery and Inclusive Society Partnership (CRISP)" funded by Horizon 2020 under the Marie Sklodowska-Curie Research and Innovation Staff Exchange, the paper draws on research carried out as part of an international research collaboration with U.S. colleagues and people with lived experience in both countries (see Rowe et al, 2012, Rowe 2015). Using a community based participatory research (CBPR) methodology, people with lived experience of life disruptions, such as MHPs, were placed at the forefront of the research process.

Our research aimed to develop a citizenship model within the unique social and political landscape that impacts on mental health policy, health, and social care practice in Scotland. The appointment of a dedicated Minister for Mental Health for Scotland in 2016 signalled a clear policy divergence from the rest of the UK (Mental Health Foundation, 2016). The Scottish Government set out its vision within the Mental Health Strategy (2017-2027), which calls for people's access to the right help, at the right time, with an expectation of recovery, and enjoyment of equal rights, and freedom from discrimination and stigma. Despite these developments, people with MHPs in Scotland continue to experience marginalisation, stigmatisation, discrimination, high levels of social exclusion and are at high risk of poverty (Friedli, 2009; Funk, Drew and Knapp 2012; Lanfriedi et al, 2015; www.seeme.org). Consequently, research that aimed to better understand these experiences via a citizenship lens was timely.

\section{Why citizenship?}

Citizenship as a concept is less well known within mental health policy and practice than the recovery model. The recovery process has been defined as a unique or deeply personal journey (Leamy et al, 2011) and recovery-oriented practice aims to refocus mental health services from 'treat and cure' to a more holistic and person centred approach (Davidson, 2016). At the same time, this person-centred sense of recovery has been misunderstood and misinterpreted in some policy and practice contexts; used as a justification for cutting funding for care and treatment and reducing needed services in the guise of allowing people to pursue their own personal 'recovery journeys' without adequate support (McWade, 2016, Rowe \& Davidson, 2016). Recovery has also been faulted for a lack of consensus about its application in practice and for imposing professionalised ideas onto what was originally a serviceuser led concept (Harper and Speed, 2012; Stuart et al, 2017).

The citizenship approach moves beyond the traditional, narrow view of the Scottish health care system with its focus on the management and treatment of symptoms, and challenges health and social inequalities (Campbell, 2014). Introduction of the concept of citizenship can foster an understanding of people with experience of MHPs as valued, contributing members of their communities. It can also help redefine social integration to encourage individuals' efforts to achieve the full rights and responsibilities associated with membership in society (Ware, et al, 2007). An increased sense of citizenship gained through active participation has been found to be correlated with improved quality of life and wellbeing among participants (Rowe et al, 2009; Rowe et al, 2012). 
Several social and community integration measures assess the extent of full and active participation in society (McMillan and Chavis, 1986; Resnik \& Reiber, 2012), yet little research has been conducted in the UK to understand what citizenship means to people with experience of MHPs and what factors promote or inhibit their citizenship.

\section{Developing a model of citizenship}

A CBPR approach was used to develop the model of citizenship within a Scottish context, drawing upon methods employed by Rowe et al, (2012). While CBPR is a relatively new research method, its principles and application can be traced back to participatory action research (Lewin, 1946), in which partners contribute expertise and shared decision making throughout the research process (Minkler and Wallerstein, 2003). CBPR aims to transfer 'power' from the researcher to the participants (Maclntyre et al, 2019). Consistent with a growing number of CBPR studies (Guta et al, 2013), the current research recruited and trained peers as co-researchers. In doing so, the research team sought to embody the key principles of citizenship in the research process; promoting peer's inclusion and active participation in decision making processes throughout the study. Research of this nature raises a number of challenges, ethical tensions and dilemmas, requiring that researchers practice critical reflection throughout the research process (Macintyre et al, 2019).

The current project employed "concept mapping," a method designed to produce visual representations or a map of ideas of an individual or group around a particular concept (in this case citizenship). The study adopted a widely used mixed methods participatory approach (Kane \& Trochim, 2007; Trochim, 2003). To begin, peer researchers and academic co-facilitators conducted 10 focus group discussions with people who have experienced life disruptions, including people with experience of substance misuse, the criminal justice system and long-term physical health problems and well as people who did not identity as having experienced such life disruptions. The objective was to capture a broad range of perspectives and experiences to inform the conceptual model of citizenship. Seventyseven people participated in the focus groups, which were audiotaped and transcribed verbatim. Research team members then read and reread the transcripts and identified 110 citizenship statements.

Stakeholders from each of the focus groups were then invited to participate in concept mapping sessions in which they sorted the list of 110 citizenship statements into at least two piles, based on what they saw as their similarities. Participants $(n=45)$ were then asked to rate each of the 110 statements on a 5-point Likert scale as to each item's importance related to citizenship and to their level of achievement of the statement. An additional 245 participants then rated each of the statements in terms of their clarity and relevance. Data was then analysed using multivariate statistical methods of multidimensional scaling and hierarchical cluster analysis (Trochim, 2003). It is our intention that the resulting model of citizenship (Maclntyre et al, forthcoming) will be applied in policy and practice and inform the development of a measure tool that can be implemented in health and social care practice in Scotland.

Implementing a citizenship approach will require a broad and holistic understanding of the multifaceted issues that contribute to mental health in Scotland. This, in turn, will require a culture shift at policy and practice levels. Despite the influence of the disability movement, proponents of the social model of disability, and the recovery movement, understandings of mental health and illness remain heavily influenced by the medical model (Tew, 2011; Davidson et al, 2016; Maclntyre, 2018). Indeed, Eiora-Orosa and Rowe (2017) argue that taking a novel concept such as citizenship and applying it within the field of mental health can result in difficulties in understanding and appreciating the applicability of 
the concept across different socio-cultural environments. They also identify resistance to and lack of motivation for change as potential barriers to implementation.

Successful implementation of citizenship-oriented care will require giving clinicians, working within traditional models of mental health, time to explore the key principles, processes, and practices of citizenship-oriented care and practices. Eiora-Orosa and Rowe (2017) argue that bottom up (service user-led) and top down change (administrator-led) is also required to effect the cultural shift proposed here. In addition, people with lived experience of MHPs and other life disrupting events must continue to be involved in the development of citizenship measures (Maclntyre et al, 2019) and in training, education and facilitation of citizenship programmes (Stewart et al, 2017).

\section{Conclusion}

Citizenship is a relatively new concept in the Scottish mental health context. Citizenship, it is argued, is intertwined with the concept of recovery, which has been more widely applied within policy and practice in Scotland. Taken together, these concepts offer a powerful way to understand the lived experience of people with life disruptions, such as MHPs, and to challenge the disadvantage they often face. Through engaging in international collaborative research, using a CBPR approach, we strive to develop a model of citizenship that is grounded in people's lived experiences and perspectives of what citizenship means to them. The aim of implementing this model in policy and practice, will be to encourage the meaningful social inclusion of people with experience of MHPs and/or other life disrupting events through promoting citizenship orientated care. We also envisage that the model will inform the development of a measurement tool for use in health and social care practice in Scotland. Overcoming resistance towards implementing a citizenship approach will entail continued peer involvement and partnership working with stakeholder groups at all levels of the health and social care system. Education, training and culture shift are required to fully embed a citizenship approach in policy and practice in Scotland. 


\section{References}

Campbell, C. (2014). Community mobilisation in the 21st century: updating our theory of social change? Journal of Health Psychology, 19, 46-59. doi: 10.1177/ 1359105313500262

Davidson, G., Campbell, J., Shannon, C. and Mulholland, C. (2016) Models of mental health, London: Palgrave MacMillan

Davidson, L. (2016) The Recovery Movement: Implications For Mental Health Care And Enabling People To Participate Fully In Life, Health Affairs, 35, 6.

Friedli, L. (2009) Mental health, resilience and inequalities, Denmark: World Health Organisation http://www.euro.who.int/ data/assets/pdf file/0012/100821/E92227.pdf

Funk, M., Drew, N. and Knapp, M. (2012) Mental health, poverty and development, Journal of Public Mental Health, 11 (4): 166-185, https://doi.org/10.1108/17465721211289356

Harper, D. and Speed, E. (2012) 'Uncovering recovery: the resistable rise of recovery and resilience' Studies in Social Justice, 6(1): pp 9-25.

Kane, M., \& Trochim, W. M. K. (2007). Concept mapping for planning and evaluation. Thousand Oaks, CA: Sage Publications.

Leamy, M, Bird, V, Le Boutillier, C, Williams, J, Slade, M. (2011) Conceptual framework for personal recovery in mental health: systematic review and narrative synthesis. British Journal of Psychiatry, 199: $445-52$.

Lewin, K. (1946) Action research and minority problems. J Soc. Issues 2(4): 34-46.

Maclntyre, G. (2018) 'Mental health services' in Cree, V. and Smith, M. (Eds) Social Work in a changing Scotland, Abingdon: Routledge

Maclntyre, G., Cogan, N., Stewart, A., Quinn, N., Rowe, M., O'Connell, M., Easton. D., Hamill, L., Igoe, M., Johnston, G., McFadden. A., and Robinson, J. (2019) Understanding citizenship within a health and social care context in Scotland using community based participatory research methods: Sage Methods Case Study, London: Sage.

McMillan, D., \& Chavis, D. (1986). Sense of community: A definition and theory. Journal of Community Psychology, 14, 6-23.

McWade, B. (2016). 'Recovery as policy as a form of neoliberal state making', Intersectionalities, 5(3): 62-79.

Mental Health Foundation (2016) Mental health in Scotland: Fundamental Facts https://www.mentalhealth.org.uk/publications/mental-health-scotland-fundamental-facts

Minkler, M. and Wallerstein, N. (2008) Community based participatory research: from process to outcomes, San Francisco: Jossey-Bass.

Resnik L, Reiber G. Long-term disabilities associated with combat casualties: measuring disability and reintegration in combat veterans. J Am Acad Orthop Surg. 2012;20(suppl 1):S31-S34.

Rowe, M. and Davidson, L. (2016) Recovering citizenship, Israel Journal of Psychiatry, 53 (1): 14-22. 
Rowe, M., Clayton, A., Benedict, P., Bellamy, C., Antunes, K., Miller, R., Pelletier, J.F., Stern, E. and O'Connell, M. (2012) Going to the source: Creating a citizenship measure by community participatory research methods, Psychiatric Services, 63 (5): 445-450.

Rowe, M., Benedict, P., Sells, D., Dinzeo, T., Garvin, C., Schwab L., , Baranoski, M., Girard V. and Chyrell Bellamy, C. (2009) Citizenship, Community, and Recovery: A Group- and Peer-Based Intervention for Persons With Co-Occurring Disorders and Criminal Justice Histories, Journal of Groups in Addiction \& Recovery, 4 (4): 224-244, DOI: 10.1080/15560350903340874

Scottish Government (2017) The Scottish Government's approach to mental health from 2017-2027 a 10 year vision https://www.gov.scot/publications/mental-health-strategy-2017-2027/

SeeMe (2017) Call to tackle mental health stigma in 2017 as new research https://www.seemescotland.org/news-and-blogs/call-to-tackle-mental-health-stigma-in-2017-asnew-research-released/released

Stewart, A., Black, K., Benedict, P. and Benson, P. (2017) Constructing community to achieve citizenship using recognition theory, recovery and citizenship as a reflective lens: Experiences from the United States and Scotland, American Journal of Psychiatric Rehabilitation, 20 (3): 234-250.

Stuart, S., Tansey, L. and Quayle, E. (2017) What we talk about when we talk about recovery: a systematic and best-fit framework synthesis of qualitative literature, Journal of Mental Health, 26 (3): 291-304

Tew, J. (2011) Social approaches to mental distress, Basingstoke: Palgrave MacMillan

Trochim, W. (2003). Research methods: The concise knowledge base. Cincinnati, OH: Atomic Dog.

Ware, N. C., Hopper, K., Tugenberg, T., Dickey, B., \& Fisher, D. (2007). Connectedness and citizenship: Redefining social integration. Psychiatric Services, 58(4), 469-474. 